\title{
Molecular characterization of the virulent infectious hematopoietic necrosis virus (IHNV) strain $220-90$
}

\author{
Arun Ammayappan ${ }^{1,2}$, Scott E LaPatra ${ }^{3}$, Vikram N Vakharia ${ }^{1 *}$
}

\begin{abstract}
Background: Infectious hematopoietic necrosis virus (IHNV) is the type species of the genus Novirhabdovirus, within the family Rhabdoviridae, infecting several species of wild and hatchery reared salmonids. Similar to other rhabdoviruses, IHNV has a linear single-stranded, negative-sense RNA genome of approximately 11,000 nucleotides. The IHNV genome encodes six genes; the nucleocapsid, phosphoprotein, matrix protein, glycoprotein, non-virion protein and polymerase protein genes, respectively. This study describes molecular characterization of the virulent IHNV strain 220-90, belonging to the M genogroup, and its phylogenetic relationships with available sequences of IHNV isolates worldwide.

Results: The complete genomic sequence of IHNV strain 220-90 was determined from the DNA of six overlapping clones obtained by RT-PCR amplification of genomic RNA. The complete genome sequence of 220-90 comprises 11,133 nucleotides (GenBank GQ413939) with the gene order of 3'-N-P-M-G-NV-L-5'. These genes are separated by conserved gene junctions, with di-nucleotide gene spacers. An additional uracil nucleotide was found at the end of the $5^{\prime}$-trailer region, which was not reported before in other IHNV strains. The first 15 of the 16 nucleotides at the $3^{\prime}$ - and 5'-termini of the genome are complementary, and the first 4 nucleotides at 3'-ends of the IHNV are identical to other novirhadoviruses. Sequence homology and phylogenetic analysis of the glycoprotein genes show that 220-90 strain is $97 \%$ identical to most of the IHNV strains. Comparison of the virulent 220-90 genomic sequences with less virulent WRAC isolate shows more than 300 nucleotides changes in the genome, which doesn't allow one to speculate putative residues involved in the virulence of IHNV.

Conclusion: We have molecularly characterized one of the well studied IHNV isolates, 220-90 of genogroup M, which is virulent for rainbow trout, and compared phylogenetic relationship with North American and other strains. Determination of the complete nucleotide sequence is essential for future studies on pathogenesis of IHNV using a reverse genetics approach and developing efficient control strategies.
\end{abstract}

\section{Background}

The infectious hematopoietic necrosis virus (IHNV) is probably one of the most important fish viral pathogens causing acute, systemic and often virulent disease predominantly in both wild and cultured salmon and trout $[1,2]$. The first reported epidemics of IHNV occurred in sockeye salmon (Oncorhynchus nerka) fry at Washington and Oregon fish hatcheries during the 1950s [3-5]. IHNV is native to salmonids of the Pacific Northwest

\footnotetext{
* Correspondence: vakharia@umbi.umd.edu

${ }^{1}$ Center of Marine Biotechnology, University of Maryland Biotechnology Institute, Baltimore, 701 East Pratt Street, Baltimore, Maryland 21202-3101,
} USA

(c) 2010 Ammayappan et al; licensee BioMed Central Ltd. This is an Open Access article distributed under the terms of the Creative Commons Attribution License (http://creativecommons.org/licenses/by/2.0), which permits unrestricted use, distribution, and reproduction in any medium, provided the original work is properly cited. region of North America and its current geographical range extends from Alaska to northern California along the Pacific coast and inland to Idaho $[1,6]$. IHNV has spread to Asia and Europe, most likely due to the movement of infected fish and eggs [2].

As for all the Rhabdoviridae, the genome of IHNV consists of a single-stranded negative-sense RNA. The gene order of IHNV is 3'-leader-N-P-M-G-NV-L-trailer5' [7]. The negative-strand RNA genome is connected tightly with the nucleoprotein $\mathrm{N}$ and forms the core structure of virion. This encapsidated genomic RNA is also associated with the phosphoprotein $\mathrm{P}$ and polymerase protein $\mathrm{L}$, which is involved in viral protein 
synthesis and replication. Their genome codes for five structural proteins, a nucleoprotein $(\mathrm{N})$, a polymeraseassociated protein $(\mathrm{P})$, a matrix protein $(\mathrm{M})$, an RNAdependent RNA polymerase (L) and a surface glycoprotein $(\mathrm{G})$, and a nonstructural protein (NV).

The diversity among IHNV isolates in the Hagerman Valley region was first reported by LaPatra, who used monoclonal and polyclonal antibodies to examine the heterogeneity of serum neutralization profiles of 106 IHNV isolates at four rainbow trout culture facilities between 1990 and 1992 [8,9]. Ten different serum neutralization groups were found, with three groups representing the majority (91\%) of the isolates. Later, based on partial sequence analyses of the $G$ gene of 323 field isolates, three major genetic groups of IHNV were defined, designated as the $\mathrm{U}, \mathrm{M}$, and $\mathrm{L}$ genogroups $[10,11]$. The $M$ genogroup is endemic in the rainbow trout farming region in Idaho where phylogenetically distinct sub-groups, designated MA-MD have been reported [12]. The $M B, M C$, and $M D$ sub-groups are the three most prevalent and widely distributed types of IHNV in the virus-endemic region, and they have been shown to co-circulate in the field for over 20 years [12]. To date, the complete nucleotide sequence of low virulence WRAC strain, belonging to the MA sub-group, and strain $\mathrm{K}$ (Kinkelin, France) has been determined $[13,14]$. Isolate $220-90$ of the MB sub-group is virulent to rainbow trout and widely used as a challenge virus in many studies [8-12]. However, the complete nucleotide sequence of this isolate is not available. Therefore, to find out the molecular characteristics of IHNV isolate 220-90, we analyzed the entire genomic sequences and compared it with other IHNV strains.

\section{Methods}

\section{Cells and Viruses}

The IHNV strain 220-90 was kindly provided by Scott LaPatra, Clear Springs Foods Inc., Idaho, USA. The virus was initially recovered from acutely infected juvenile rainbow trout during routine examinations of hatchery-reared fish, conducted from 1990 to 1992 in the Hagerman Valley, Idaho, USA [8]. Specimens for virus isolation were collected when mortality increased above 200 fish day $^{-1}$. Viruses were isolated and identified by methods previously described [15]. The epithelioma papulosum cyprini (EPC) cell line from common carp Cyprinus carpio [16] was used for the isolation, propagation, and identification of IHNV isolates. Cells were propagated in minimum essential medium (MEM) supplemented with $10 \%$ fetal bovine serum and $2 \mathrm{mM} \mathrm{L-}$ glutamine (ATCC, Manassas, VA). For routine cell propagation, the EPC cells were incubated at $28^{\circ} \mathrm{C}$. To propagate the virus, the cells were infected and incubated at $14^{\circ} \mathrm{C}$ until cytopathic effects were complete. The supernatant was collected 5 days post-infection, clarified and stored at $-80^{\circ} \mathrm{C}$ for further processing.

Table 1 Oligonucleotides used for cloning and sequencing of the IHNV genome

\begin{tabular}{|c|c|c|}
\hline IHNV primers & Sequences & Position \\
\hline IHNV 1F & GTATAAGAAAAGTAACTTGAC & $1-21$ \\
\hline IHNV 1R & CTTCCCTCGTATTCATCCTC & $2097-2078$ \\
\hline IHNV 2F & GCAGGATCCCAAGAGGTGAAG & 2033-2053 \\
\hline IHNV 2R & GGAACGAGAGGATTTCTGATCC & 3819-3818 \\
\hline IHNV 3F & CAGTGGATACGGACAGATCTC & $3767-3787$ \\
\hline IHNV 3R & CTTGGGAGCTCTCCTGACTTG & $5579-5559$ \\
\hline IHNV 4F & GTACTTCACAGATCGAGGATCG & $5523-5544$ \\
\hline IHNV 4R & CGGGGACTCTTGTTCTGGAATG & $7147-7128$ \\
\hline IHNV 5F & CGTACCAGTGGAAATACATCGG & 7098-7119 \\
\hline IHNV 5R & CAGGTGGTGAAGTAGGTGTAG & 9018-8997 \\
\hline IHNV 6F & GAGGGAGTTCTTTGATATTCCC & $8931-8952$ \\
\hline IHNV 6R & ATAAAAAAAGTAACAGAAGGGTTCTC & 11130-11105 \\
\hline IHNV NheR & CGTTCTGCTAGCTTGTTGTTGG & $525-503$ \\
\hline IHNV 1MF & ACAGAAGCTAACCAAGGCTAT & 729-749 \\
\hline IHNV 2MF & AGATCCCAATGCAGACCTACT & $2610-2630$ \\
\hline IHNV 3MF & GTATCAGGGATCTCCATCAG & $4322-4341$ \\
\hline IHNV 4MF & GATACATAAACGCATACCACA & $6113-6133$ \\
\hline IHNV 5MF & TCAGAGATGAAGCTCAGCAA & $7546-7565$ \\
\hline IHNV 6MF & AACACCATGCAGACCATACTC & $9559-9579$ \\
\hline IHNV 5'End & CGATATTGAAGAGAAAGGAATAAC & $10692-10715$ \\
\hline Oligo (dT) & GCGGCCGCTTTTTाTTTTाTTTाTाTाT & \\
\hline
\end{tabular}




\section{RT-PCR amplification of the IHNV genome}

Viral RNA was extracted from cell culture supernatant using Qiagen RNAeasy kit, according to manufacturer's instructions (Qiagen, Valencia, CA), and stored at $-20^{\circ} \mathrm{C}$. The consensus PCR primers were designed using published IHNV genome sequences (GenBank accession numbers X89213; L40883) from the National Center for Biotechnology Information (NCBI). The complete genome sequences were aligned, and highly conserved sequence segments were identified and used to design overlapping primers. The oligonucleotide primers used in this study are listed in Table 1. RT-PCR amplification of the IHNV genome was carried out essentially as described for viral hemorrhagic septicemia virus (VHSV), using Superscript III RT ${ }^{\mathrm{TM}}$ and $p f x 50^{\mathrm{Tm}}$ PCR kits from Invitrogen, Carlsbad, CA [17]. The RT-PCR products were purified and cloned into a pCR2.1 TOPO ${ }^{\circledR}$ TA vector from Invitrogen.

To identify the 3'-terminal region of the genomic RNA, viral RNA was polyadenylated as described previously (17), and used as a template for RT-PCR amplification. The cDNA was reverse transcribed using an oligo (dT) primer (5'-GCGGCCGCTTTTTTTTTTT TTTTTTTTTT-3'), followed by PCR with the IHNVspecific primer NheR (5'- CGTTTCTGCTAGCTT GTTGTTGG-3'). The 5'-terminal of genomic RNA was identified by rapid amplification of the 5 '-end, using a 5'RACE kit (Invitrogen, Carlsbad, CA), according to manufacturer's instructions.

\section{Sequence and phylogenetic tree analysis}

Plasmid DNA from various cDNA clones was sequenced by dideoxy chain termination method, using an automated DNA sequencer (Applied Biosystems Inc., Foster City, CA). Three independent clones were sequenced for each amplicon to exclude errors that can occur from RT and PCR reactions. The assembly of contiguous sequences and multiple sequence alignments were performed with the GeneDoc software [18]. The pairwise nucleotide identity and comparative sequence analyses were conducted using Vector NTI Advance 10 software (Invitrogen, CA) and BLAST search, NCBI. Phylogenetic analyses were conducted using the MEGA4 software [19]. Construction of a phylogenetic tree was performed using the ClustalW multiple alignment algorithm and Neighbor-Joining method with 1000 bootstrap replicates.

\section{Database accession numbers}

The complete genome sequence of IHNV 220-90 strain has been deposited in GenBank with the accession no. GQ413939. The accession numbers of other viral sequences used for sequence comparison and phylogenetic analysis are listed (see additional File 1: Information about the infectious hematopoietic necrosis virus (IHNV) isolates used in this study for comparison and phylogenetic analysis).

\section{Results}

The complete nucleotide sequence of $220-90$

The entire genome of IHNV 220-90 strain was amplified as six overlapping cDNA fragments that were cloned, and the DNA was sequenced (Fig. 1). The complete genome sequence of 220-90 comprises 11,133 nucleotides (nts) and contains six genes that encode the nucleocapsid $(\mathrm{N})$ protein, the phosphoprotein $(\mathrm{P})$, the matrix protein $(\mathrm{M})$, the glycoprotein $(\mathrm{G})$, the non-virion $(\mathrm{NV})$ protein, and the large $(\mathrm{L})$ protein (Fig. 1), The gene order is 3'-N-P-M-G-NV-L-5', like other novirhabdoviruses. The genomic features and predicted proteins of 220-90 are given in Table 2. All the genes are separated by untranslated sequences that are called gene

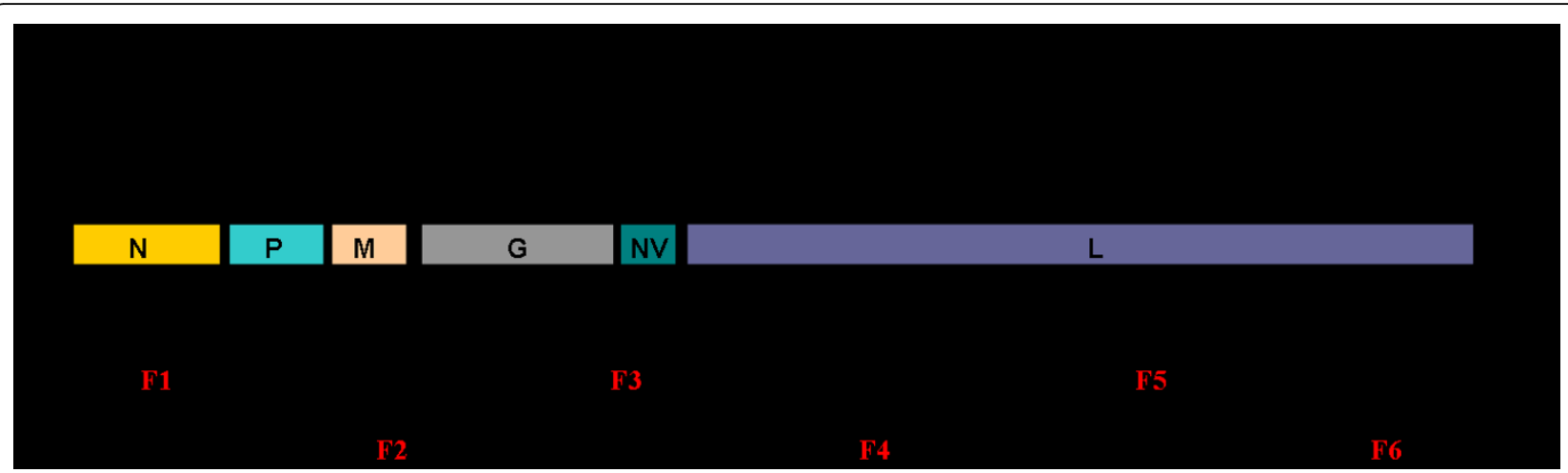

Figure 1 Genetic map of the IHNV genome and CDNA clones used for sequence analysis. The location and relative size of the IHNV ORFS are shown; the numbers indicate the starts and ends of the respective ORFs. Six cDNA fragments (F1 to F6) were synthesized from the genomic RNA by RT-PCR. The primers used for RT-PCR fragments are shown at the end of each fragment. The RNA genome is 11,133 nucleotides long and contains a leader $(L)$ and trailer $(T)$ sequences at its $3^{\prime}$-end and $5^{\prime}$-end, respectively. The coding regions of $N, P, M, G, N V$ and $L$ genes are separated by intergenic sequences, which have gene-start and gene-end signals. 
Table 2 Genomic features and predicted proteins of the IHNV strain 220-90

\begin{tabular}{|c|c|c|c|c|c|c|c|c|c|}
\hline S. No & Gene & Start & End & 5'UTR & ORF & 3'UTR & $\begin{array}{l}\text { Total } \\
\text { Length }^{\mathrm{a}}\end{array}$ & $\begin{array}{l}\text { Protein } \\
\text { Size (aa) }\end{array}$ & $\mathrm{MW}^{\mathrm{b}} \mathrm{kDa}$ \\
\hline 1. & Leader & 1 & 60 & & & & 60 & & \\
\hline 2. & $\mathrm{~N}$ & 63 & 1430 & 112 & 1176 & 80 & 1638 & 391 & 42.3 \\
\hline 3. & $P$ & 1433 & 2199 & 33 & 693 & 41 & 767 & 230 & 26.0 \\
\hline 4. & M & 2202 & 2945 & 53 & 588 & 103 & 744 & 195 & 22.0 \\
\hline 5. & G & 2948 & 4567 & 51 & 1527 & 42 & 1620 & 508 & 56.6 \\
\hline 6. & NV & 4570 & 4938 & 26 & 336 & 7 & 369 & 111 & 13.2 \\
\hline 7. & $L$ & 4941 & 11031 & 76 & 5961 & 54 & 6091 & 1986 & 225.0 \\
\hline 8. & Trailer & 11032 & 11133 & & & & 102 & & \\
\hline
\end{tabular}

a Total length of a gene including 5'UTR, ORF and $3^{\prime} U T R$

${ }^{b}$ Predicted molecular weight of proteins in kilodaltons $(\mathrm{kDa})$

junctions. The untranslated regions at the 3 ' and 5 ' ends are called the 'leader' and 'trailer', respectively. An additional uracil nucleotide was found at the end of the 5'trailer region, which was not reported before in other IHNV strains.

\section{ORF 1 or Nucleocapsid $(\mathrm{N})$ protein gene}

The first ORF, extending from nts 175-1350, contains 391 residues and it encodes nucleoprotein $(\mathrm{N})$ with a deduced molecular mass of $42 \mathrm{kDa}$. The $\mathrm{N}$ gene starts with the conserved sequence (CGUG) and has the putative polyadenylation signal (UCUUUUUUU). The 5'untranslated region of $174 \mathrm{nts}$ is followed by the first AUG codon of the 1176 nts open reading frame (ORF). Comparison of the published IHNV nucleoprotein sequences with IHNV 220-90 shows that it is $98 \%$ identical to the 193-110, HO-7 and LR-80 isolates (Table 3). The ORF 1 has 5' untranslated region of 112 nts (from putative gene start to AUG) and 3' untranslated region of 80 nts (from stop codon to the gene end).

\section{ORF 2 or Phosphoprotein $(P)$ gene}

The $\mathrm{P}$ gene of $220-90$ is $767 \mathrm{nts}$ long and encodes a protein of 230 amino acids (aa) with a predicted MW of $26.0 \mathrm{kDa}$ (Table 2). The predicted P protein contains 6 serine, 5 threonine and 1 tyrosine residues, identified as possible phosphorylation sites using NetPhos 2.0 server http://www.cbs.dtu.dk/. Among novirhabdoviruses, the IHNV-P protein has an amino acid sequence identity of $35 \%$ with viral hemorrhagic septicemia virus (VHSV), $65 \%$ with Hirame rhabdovirus (HIRRV), and 30\% with snakehead rhabdovirus (SHRV) (Table 3).

\section{ORF 3 or Matrix (M) gene}

The $\mathrm{M}$ gene of $220-90$ is $744 \mathrm{nts}$ long and encodes an $\mathrm{M}$ protein of 195 aa residues with a predicted MW of $22.0 \mathrm{kDa}$ (Table 2). Among novirhabdoviruses, the M protein has an amino acid sequence identity of $36 \%$ with VHSV, 74\% with HIRRV, 35\% with SHRV (Table 3). A 5 '-untranslated region of 53 nts is followed by an ORF and succeeded by 103 nts 3' UTR.

\section{ORF 4 or glycoprotein (G) gene}

The gene for the $\mathrm{G}$ protein is located between 2948 and $4567 \mathrm{nts}$ from the 3'-end of the viral genome. A 3' UTR of $51 \mathrm{nts}$ is followed by an ORF (nts 1524) that encodes a polypeptide of 508 aa residues, with a calculated MW of $56.6 \mathrm{kDa}$, and succeeded by $42 \mathrm{nts} 3$ ' UTR. The predicted G protein contains 20 serine, 6 threonine and 6 tyrosine residues, identified as possible phosphorylation sites using NetPhos 2.0 server http://www.cbs.dtu.dk/. Four putative $\mathrm{N}$-glycosylation sites were identified at amino acids 56-59 (NASQ), 400-403 (NNTT), 401-404 (NTTI) and 438-441(NETD) and one O-glycosylation were identified at amino acid position 492 . We compared the G protein of 28 IHNV strains from different parts of the world. The regions between amino acid positions 32-52, 131-204, 289-369, 380-416 are highly conserved. The regions between amino acids 247-257 and 269-276 have a greater genetic diversity than any other part of the G protein. The IHNV glycoprotein has the following domains: signal peptide at $\mathrm{N}$-terminal (120aa), ectodomain (21-459aa), transmembrane domain (460-482 aa) and endodomain (483-508 aa), which were predicted by SignalP server http://www.cbs.dtu.dk/services/SignalP/.

\section{ORF 5 or Non-virion (NV) protein gene}

The NV protein gene is located between 4570 and 4938 nts from the 3'-end of the viral genome. It encodes a polypeptide of 111 aa residues, with a calculated molecular mass of $13.2 \mathrm{kDa}$. The predicted NV protein contains 1 serine, 2 threonine and 1 tyrosine residues, identified as possible phosphorylation sites using NetPhos 2.0 server http://www.cbs.dtu.dk/. The function of $\mathrm{NV}$ protein is not clearly known. NV is a non-structural protein of novirhabdoviruses, which could be detected only in the infected cells [20].

\section{ORF 6 or Polymerase (L) gene}

ORF 6 encodes the largest protein, the polymerase, which starts at position 5017 and ends at position 
Table 3 Percent (\%) nucleotide or deduced amino acid identity of the IHNV strain 220-90 with other IHNV strains and Novirhabdoviruses $^{\text {a }}$

\begin{tabular}{|c|c|c|c|c|c|c|c|c|}
\hline IHNV Strains & $3^{\prime}$ Leader $^{*}$ & $\mathrm{~N}$ & $\mathbf{P}$ & $M$ & G & NV & $\mathbf{L}$ & $5^{\prime}$ Trailer $^{*}$ \\
\hline 193-110 & - & 98 & - & - & 97 & 96 & - & - \\
\hline 332 & - & - & - & - & 97 & - & - & - \\
\hline Auke77 & - & - & - & - & 97 & - & - & - \\
\hline Carson-89 & - & 96 & - & - & 97 & - & - & - \\
\hline Col-80 & - & 95 & - & - & 96 & - & - & - \\
\hline Col-85 & - & 95 & - & - & 96 & - & - & - \\
\hline Cro/05 & - & - & - & - & 97 & 96 & - & - \\
\hline CST-82 & - & 97 & - & - & 97 & 96 & - & - \\
\hline G4 & - & - & - & - & 96 & - & - & - \\
\hline IHNV-PRT & - & 93 & 95 & 98 & 95 & 95 & - & - \\
\hline FR0031 & - & - & - & - & 96 & - & - & - \\
\hline FF030-91 & - & - & - & - & 96 & - & - & - \\
\hline Fs42/95 & - & - & - & - & 97 & 97 & - & - \\
\hline Fs62/95 & - & - & - & - & 97 & - & - & - \\
\hline FsKV88 & - & - & - & - & 97 & - & - & - \\
\hline FsVi100/96 & - & - & - & - & 97 & - & - & - \\
\hline$\overline{\mathrm{HO}-7}$ & - & 98 & - & - & 97 & 97 & - & - \\
\hline HV7601 & - & - & - & 98 & 97 & 97 & - & - \\
\hline J04321 & - & 95 & - & - & - & - & - & - \\
\hline LB91KI & - & 96 & - & - & - & - & - & - \\
\hline LR-73 & - & 95 & - & - & 97 & 96 & - & - \\
\hline LR-80 & - & 98 & - & - & 97 & 97 & - & - \\
\hline LWS-87 & - & 96 & - & - & 97 & - & - & - \\
\hline$\overline{\text { WRAC }}$ & 96 & 97 & 98 & 98 & 97 & 96 & 98 & 96 \\
\hline RB-76 & - & 96 & - & - & 97 & - & - & - \\
\hline RB-1 & - & 96 & - & - & 97 & 97 & - & - \\
\hline$\overline{R t U i 02}$ & - & - & - & - & 94 & - & - & - \\
\hline$\overline{\text { SRCV }}$ & - & 95 & - & - & 96 & - & - & - \\
\hline Strain K & - & 97 & 97 & 98 & 97 & 97 & 98 & - \\
\hline X89213 & 96 & 97 & 97 & 98 & 97 & 97 & 98 & 95 \\
\hline HIRRV & 64 & 62 & 65 & 74 & 74 & 53 & 84 & 71 \\
\hline SHRV & 44 & 42 & 30 & 35 & 39 & 10 & 58 & 36 \\
\hline VHSV & 41 & 40 & 35 & 36 & 38 & 10 & 60 & 29 \\
\hline
\end{tabular}

a more than $95 \%$ identities are shown in bold letters

* only nucleotide sequences were used for analysis

Viruses belonging to Novirhabdovirus genus are in bold letters

HIRRV, Hirame rhabdovirus; SHRV, Snakehead rhabdovirus; VHSV, Viral hemorrhagic septicemia virus

10977. It encodes a polypeptide of 1986 aa residues, with a deduced molecular mass of $225.0 \mathrm{kDa}$. The $\mathrm{L}$ protein contains 67 serine, 38 threonine and 9 tyrosine residues as possible phosphorylation sites. The predicted RNA-dependent RNA polymerase ( $R d R p)$ domain is situated between residues 18 and 1159. The deduced $\mathrm{L}$ protein of IHNV exhibits 60\%, 84\%, and 58\% identities with VHSV, HIRRV and SHRV, respectively (Table 3).

The Genomic termini and untranslated sequences

Rhabdoviruses have conserved untranslated regions between open reading frames for optimal translation of viral proteins [21]. These sequences consist of a putative transcription stop/polyadenylation motif (UCURUCU ${ }^{7}$ ) which signals reiterative copying of the $U$ sequences to generate poly (A) tail to the mRNA. This sequence is followed by an intergenic di-nucleotide AC or GC which are not transcribed, and a putative transcription start signal, CGUG (Fig. 2A). The gene junctions of different novirhabdoviruses are shown in Table 4.

The untranslated region of 3' leader and 5' trailer are $60 \mathrm{nts}$ and $102 \mathrm{nts}$ in length, respectively. The 3' leader of $220-90$ is $63 \% \mathrm{~A} / \mathrm{T}$ rich, whereas 5 trailer is $60 \% \mathrm{~A} / \mathrm{T}$ 


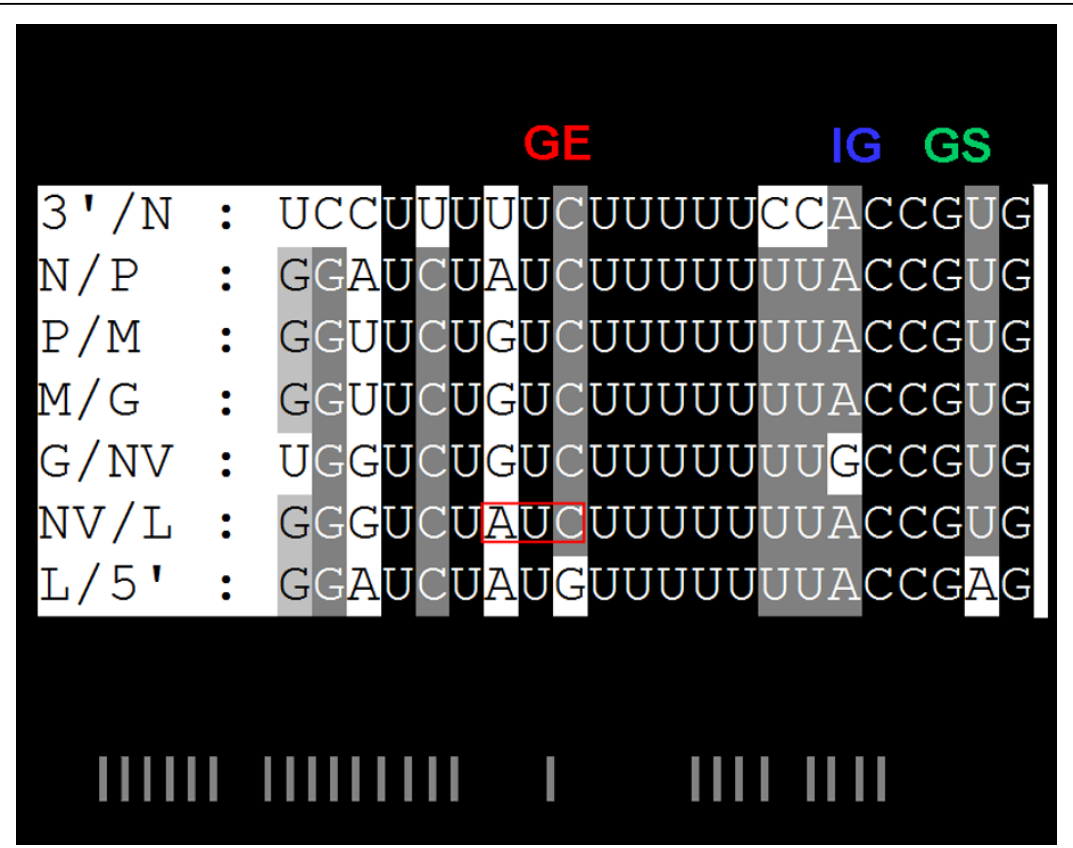

Figure 2 Analysis of the gene junctions and complementarities in the IHNV genome. A) Seven identified gene junctions of IHNV in the negative-sense of the genomic RNA are shown. 3'/N, junction of 3'-leader and nucleocapsid gene; N/P, junction of nucleocapsid and phosphoprotein gene; $P / M$, junction of phosphoprotein and matrix gene; $M / G$, junction of matrix and glycoprotein gene; G/NV, junction of glycoprotein and non-virion gene; NV/L, junction of non-virion and polymerase gene; $L / 5^{\prime}-$, junction of polymerase gene and $5^{\prime}$ trailer. $G E=$ Gene end; IG = Intergenic di-nucleotide; GS = Gene start. The stop codon of NV ORF is merged with gene end sequence and is shown in red box. B) Complementarities of the $3^{\prime}$ - and $5^{\prime}$-ends of the IHNV genome. The first 15 of the 16 nucleotides at the $3^{\prime}$-end are complementary to the 5'-end nucleotides of genomic RNA.

rich. Like other rhabdoviruses, the genomic termini of IHNV 3'-terminal nucleotides exhibit complementarities to the nucleotides of 5'-terminus of the genomic RNA (Fig. 2B). The complementary nature of genomic termini involves the formation of a panhandle structure, which is important for replication of rhabdoviruses.

\section{Homology and phylogenetic analysis}

Phylogenetic trees were generated from the nucleotide sequences of the ORFs and of the complete genome.
The complete genome and gene proteins of IHNV were also compared with different members of novirhabdoviruses and the results are shown in Tables 3 and 4 . Among novirhabdoviruses, HIRRV is closely related to IHNV and has an identity of $72 \%$. Comparison of the UTRs and protein coding sequences of 220-90 strain with novirhabdoviruses shows that non-virion protein is highly variable than any other region of the genome (Table 3). The 3'- and 5'- UTRs are more conserved

Table 4 Comparisons of the gene junctions of the IHNV genome with other Novirhabdoviruses

\begin{tabular}{|c|c|c|c|}
\hline Type & & Gene Junctions & \\
\hline & N/P & $\mathrm{P} / \mathrm{M}$ & M/G \\
\hline IHNV & UCU AUCUUUUUUU AC CGUGAUAUCACG & UCUGUCUUUUUUU AC CGUGCGUUCACA & UCUGUCUUUUUUU AC CGUGAAAACACG \\
\hline SHRV & UCUAUCUUUUUUU GC CGUGCUCUCACG & UCUGUCUUUUUUU ACCGUGCUCUCACG & UCUGUCUUUUUUU AC CGUGCUCUCACG \\
\hline VHSV & UCUAUCUUUUUUU GC CGUGCUAAUAUU & UCUAUCUUUUUUU GC CGUGCUGACAAG & UCUAUCUUUUUUU AC CGUGUAAACACA \\
\hline HIRRV & UCUAUCUUUUUUU AC CGUGCAAACACA & UCUAUCUUUUUUU AC CGUGCAAUCACA & UCUAUCUUUUUUU AC CGUGUAAACACA \\
\hline & G/NV & $\mathrm{NV/L}$ & \\
\hline IHNV & UCUGUCUUUUUUU GC CGUGUAAACACG & UCUAUCUUUUUUU AC CGUGAAAACACG & \\
\hline SHRV & UCUGUCUUUUUUUU GC CGUGAUAUCACG & UCUAUCUUUUUUU GC CGUGCAUUACACG & \\
\hline VHSV & UCUAUCUUUUUUU AC CGUGGAAAUACU & UCUAUCUUUUUUU AC CGAGAAAACAAC & \\
\hline HIRRV & UCUAUCUUUUUUU GC CGUGUAUACAGA & UCUAUCUUUUUUU AC CGUGAACACACG & \\
\hline
\end{tabular}

The gene junctions shown here are negative-sense RNA sequences of respective viruses. IHNV, Infectious hematopoietic necrosis virus; SHRV, Snakehead rhabdovirus; VHSV, Viral hemorrhagic septicemia virus; HIRRV, Hirame rhabdovirus 


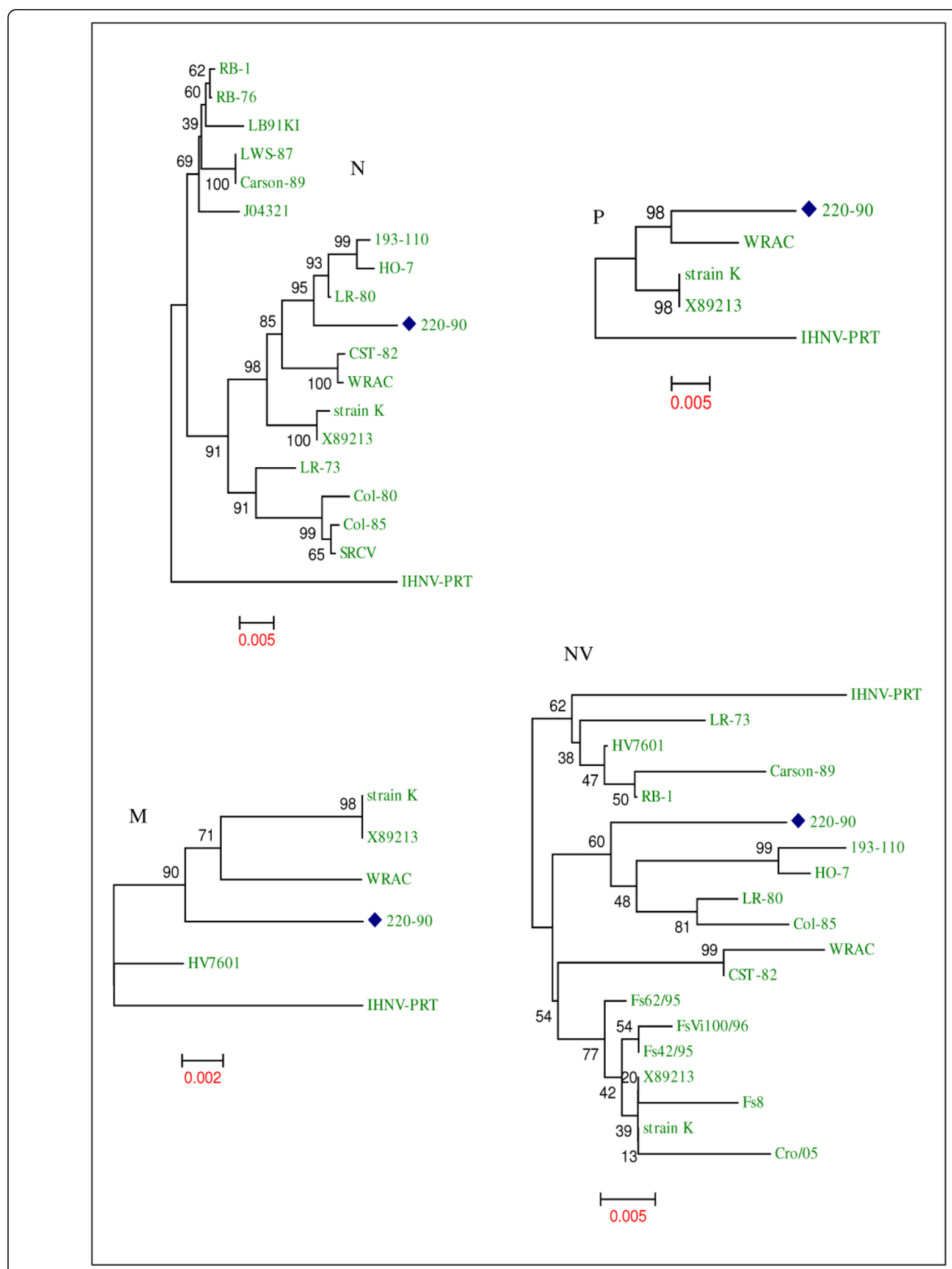

Figure 3 Phylogenetic tree analysis of sequences of nucleocapsid $(\mathrm{N})$, matrix $(\mathrm{M})$, phosphoprotein $(\mathrm{P})$, and non-virion protein (NV) of various IHNV strains. Information about the IHNV strains used in this analysis is described in additional file 1. IHNV 220-90 strain is marked with blue diamond. Phylogenetic tree analysis was conducted by neighbor-joining method using 1000 bootstrap replications. The scale at the bottom indicates the number of substitution events and bootstrap confidence values are shown at branch nodes. 
among Rhabdoviridae family members than protein coding genes (data not shown). The complete genome comparison of 220-90 with other two available sequences of IHNV strains reveals 96\% identity with WRAC, and 95\% with strain K (X89213).

The phylogenetic tree analysis of sequences of nucleocapsid (N), matrix $(\mathrm{M})$, phosphoprotein $(\mathrm{P})$, and nonvirion protein $(\mathrm{NV})$ of various IHNV strains are shown in Fig. 3. Phylogenetic analysis of the $\mathrm{N}$ gene shows clustering of 220-90 with HO-7, 193-110 and LR-80 and maintains $98 \%$ identity with those strains. Among the available sequences, WRAC strain exhibits very close identity (98\%) with 220-90 for both $\mathrm{P}$ and $\mathrm{M}$ genes. All the strains display $98 \%$ identity with the $220-90 \mathrm{M}$ gene, which demonstrates the highly conserved nature of $\mathrm{M}$ gene. When the NV genes were compared, 220-90 strain shows $95-97 \%$ identity with other IHNV strains. Previously, the North American IHNV isolates were genogrouped as $U, M$ and $L$ based on glycoprotein sequences [10]. Phylogenetic tree of the $\mathrm{G}$ genes displays that 220-90 strain belongs to the M genogroup (Fig. 4).

\section{Discussion}

A virulent IHNV strain 220-90 was isolated from the hatchery-reared juvenile rainbow trout during 90's in the Hagerman Valley, Idaho, USA [8]. IHNV is endemic throughout the Pacific Northwest region of North America, with range extending from Alaska to northern California along the Pacific coast and inland to Idaho. It causes systemic disease predominantly in both wild and cultured salmon and trout $[1,2,10]$. The disease typically occurs in rainbow trout fry maintained in the multiple outdoor rearing units of rainbow trout farm facilities $[8,12]$.

To date, the complete genome sequences are available for only two IHNV strains [13,14]. Previously, only the $\mathrm{G}$ protein gene sequence for 220-90 strain was determined (GenBank accession no. DQ164101). Comparison of the $G$ gene sequence of 220-90 isolate with the published sequence of the same shows nine nucleotide changes, which results in 7 aa changes. This may be due to different passage number of the virus in cell culture. To fully understand the molecular characteristics of a virulent IHNV, we determined the complete nucleotide sequence of 220-90 strain. The genome is $11,133 \mathrm{nts}$ long and the gene organization (N, P, M, G, NV and L) is similar to all members of the Novirhabdovirus genus. The termini of the viral genome have conserved sequences at the 3'-end (CAUAU) and at the 5'-end (GUAUA) as other members of Novirhabdovirus genus. Out of first 16 nucleotides of the 3'-terminus, 15 nucleotides are complementary to 5'-terminus of the genome (Fig. 2B), which forms the panhandle structure that may be involved in replication [22]. The length of the 3'-leader of 220-90 is $60 \mathrm{nts}$, which is similar to
HIRRV but slightly shorter than VHSV and SHRV (53 nts). IHNV has the second longest 5 ' trailer (120 nts) than other novirhabdoviruses, such as VHSV (116 nts), SHRV (42 nts), and HIRRV (73 nts). Even though the length of 3'-leader is consistent between the members of genus Novirhabdovirus, the length of the 5'-trailer is highly variable (from 42nt to $116 \mathrm{nt}$ ). It is possible that the difference in the length of trailer sequences may have some functional significance, which remains to be seen.

All the genes of VHSV start with a conserved gene start sequence (-CGUG-) like other novirhabdoviruses, followed by an ORF and conserved gene-end sequence $\left(\mathrm{A} / \mathrm{GUCUAU} / \mathrm{ACU}^{7}\right)$. All the genes end with 7 uracil (U) residues, which are polyadenylation signal for polymerase when it transcribes a gene. Polymerase adds poly (A) by stuttering mechanism [23]. After this poly (A) signal, there are two conserved intergenic di-nucleotides (G/AC), which are untranscribed and act as spacers between two genes. Polymerase skips these two nucleotides to next gene start sequence and starts transcribing next gene [23]. Transcription of rhabdovirus mRNAs is regulated by cis-acting signals located within the 3 ' leader region and untranslated region between each gene ORF [23-26]. In case of NV, the stop codon of NV gene is merged with gene-end sequences (Fig. 2A). Transcription of rhabdovirus mRNAs is regulated by cis-acting signals located within the 3 ' leader region and untranslated region between each gene ORF [23-26]. The Kozak context for each gene was compared, as shown in Fig. 5. At position -3, all the genes have adenosine (A) nucleotide, except the ORF of $\mathrm{N}$ gene.

We observed that aa residues between 1-22, 106-150 and 206-268 are highly conserved in the $\mathrm{N}$ protein, whereas residues 30-31, 41-43, 177-181, 203-205 and Cterminal region from residue 312 are variable. Phylogenetic analysis of the $\mathrm{N}$ protein shows grouping of 22090 with LR-80, HO-7 and 193-110 strains, with an identity of $98 \%$. Phylogenetic tree of the P protein shows clustering of 220-90 with WRAC strain, having an identity of $98 \%$. The matrix (M) protein is an important structural component of virion, forming a layer between the glycoprotein containing outer membrane and the nucleocapsid core. Matrix protein of IHNV is highly conserved (Table 3). IHNV strains used in this study exhibit very close (98\%) identity with 220-90. In phylogenetic analysis of $M$ protein, WRAC and strain $\mathrm{K}$, which is the same strain as Kinkelin from France (X89213), form a cluster that exhibit 99-100\% identity with each other, and 98\% identity with 220-90. Matrix protein of rhabdovirus is involved in viral assembly, condensation of nucleocapsid, formation of bullet-shaped virion $[27,28]$ and induces apoptosis by shutdown of host cell machinery in infected cells $[29,30]$. Because it 


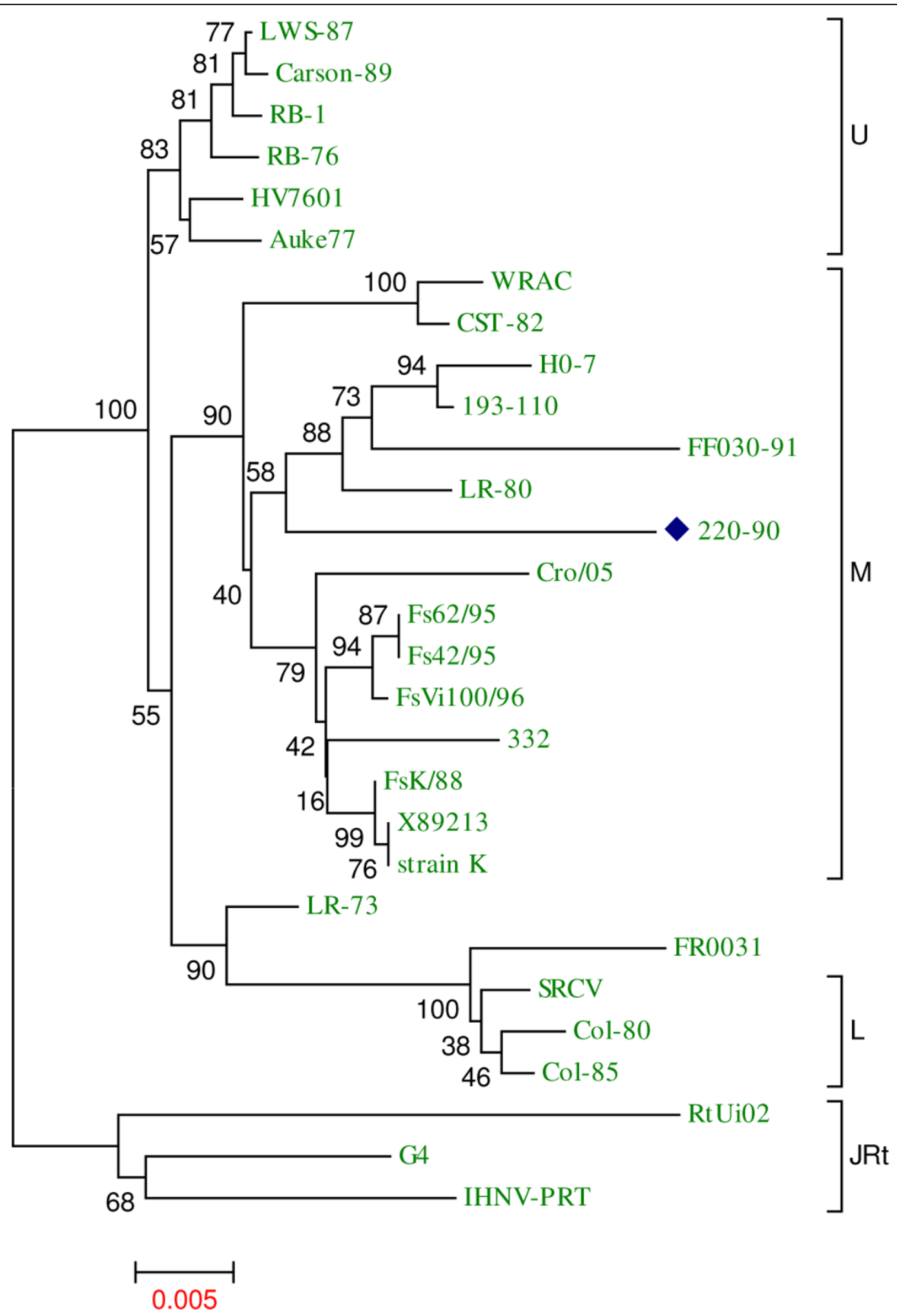

Figure 4 Phylogenetic relationship of the full-length glycoprotein (G) sequences of $\mathbf{2 8}$ IHNV strains with IHNV 220-90. Genogroups are depicted by vertical lines, as described by [10]. Brackets indicate the three major genogroups, U, M and L. IHNV 220-90 (blue diamond) is grouped under $\mathrm{M}$ genogroup. Data of virus isolates used here are available in additional file 1. Phylogenetic tree analysis was conducted by neighbor-joining method using 1000 bootstrap replications. The scale at the bottom indicates the number of substitution events and bootstrap confidence values are shown at branch nodes. 


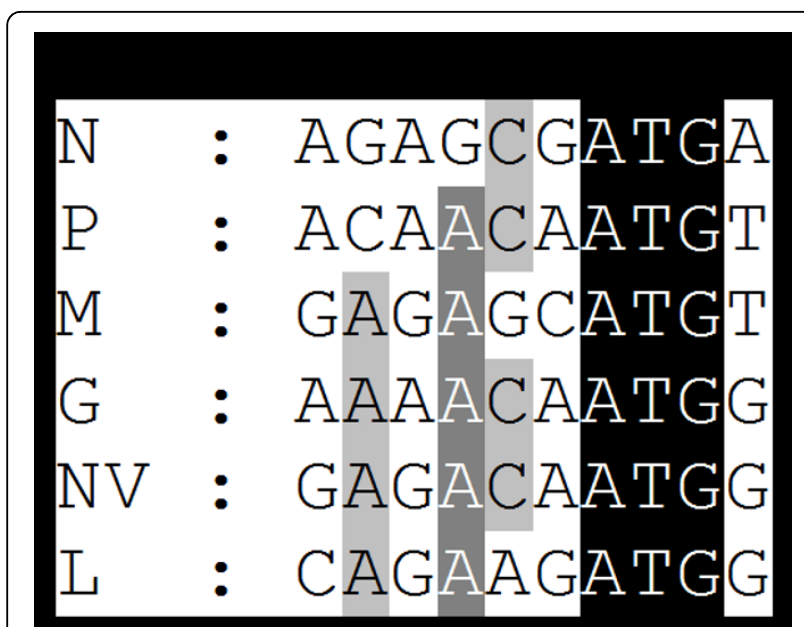

Figure 5 Kozak sequence context of each gene of IHNV 220-90 Sequences shown here are positive-sense anti-genome. * Conserved adenosine (A) at position -3. ** Start codon (ATG)

is highly essential for assembly and release of virion, the matrix protein maintains highest homology among IHNV along with the polymerase protein.

The non-virion protein (NV) of 220-90 shows identity of $95-97 \%$ with other IHNV strains. The NV protein of IHNV is conserved than counterpart of VHSV, which showed high genetic diversity [17]. It was demonstrated that NV-knockout IHNV replicated very slowly in cell culture and was non-pathogenic in fish [31]. On the contrary, NV-knockout SHRV replicated very well as wild-type virus and it was shown that NV protein of SHRV is not essential for pathogenesis [32]. These studies suggested that each species of Novirhabdovirus genus has its own characteristics and one can not ignore the importance NV in pathogenesis. The conserved nature of NV and its importance for growth and pathogenesis suggests that NV is highly essential for IHNV. All the available L sequences for IHNV strains show highest conservation (98\%) as that of matrix protein (Table 3). The $\mathrm{L}$ protein is packaged into the virus particle and is involved in both transcription and replication [23].

Genomic comparison of IHNV strains isolated from various marine species from different parts of the world sheds light on the correlation of genetic sequences with viral tropism and pathogenicity. The glycoprotein $(\mathrm{G})$ is believed to be involved in virulence and tropism because it's involvement in viral attachment and cell entry [33]. Comparison of glycoproteins of various IHNV strains has shown long blocks of conserved region (data not shown). The regions between residues $8-22$; 32-52; 131 214; 289-369; and 380-416 are highly conserved and the rest is showing genetic variations, which are scattered all over the protein. The major neutralizing epitopes have been mapped to two antigenic sites for IHNV, at amino acid residues 230-231 and 272-276 [34,35]. In this analysis, we found no amino acid substitutions at positions 230-231 among 28 strains compared. On the other hand, residues 270-276 are highly variable, which supports earlier findings $[34,35]$, and suggests the involvement of this site in antigenic variation and virulence.

A wide sequence analysis of mid-G region (303 nts) within the glycoprotein gene of 323 North American IHNV isolates revealed a maximum nucleotide diversity of $8.6 \%$, indicating low genetic diversity overall for this virus [10]. The North American IHNV isolates, genogrouped as $\mathrm{U}, \mathrm{M}$ and $\mathrm{L}$ by phylogenetic analysis, vary in topography and geographical range [10]. The phylogenetic analysis of the glycoprotein of 220-90 (Fig. 4) shows clustering with LR-80, FF030-91, 193-110 and HO-7 strains, which exhibits that 220-90 belongs to the $\mathrm{M}$ genogroup.

Additional file 1: Information about the infectious hematopoietic necrosis virus (IHNV) isolates used in this study for comparison and phylogenetic analysis

Click here for file

[http://www.biomedcentral.com/content/supplementary/1743-422X-7-10S1.DOC ]

\section{Author details}

${ }^{1}$ Center of Marine Biotechnology, University of Maryland Biotechnology Institute, Baltimore, 701 East Pratt Street, Baltimore, Maryland 21202-3101, USA. ${ }^{2}$ Department of Veterinary Medicine, University of Maryland, College Park, MD 20742, USA. ${ }^{3}$ Clear Spring Foods, Inc., Research Division, P.O. Box 712, Buhl, ID 83316, USA.

\section{Authors' contributions}

VNV and SEL conceived the study. AA planned the experimental design and carried out cloning and sequencing. AA drafted the manuscript. All authors critically reviewed and approved the final manuscript.

\section{Competing interests}

The authors declare that they have no competing interests.

Received: 16 October 2009

Accepted: 19 January 2010 Published: 19 January 2010

\section{References}

1. Wolf K: Infectious hematopoietic necrosis virus. In Fish Viruses and Fish Viral Diseases. Ithaca, NY, Cornell University Press 1988, 83-114.

2. Winton JR: Recent advances in detection and control of infectious hematopoietic necrosis virus in aquaculture. Annual Rev Fish Dis 1991, 1:83-93.

3. Rucker RR, Whippie WJ, Parvin JR, Evans CA: A contagious disease of salmon possibly of virus origin. US Fish Wildl Serv and Fish Bull 1953, 54:174-175.

4. Guenther RW, Watson SW, Rucker RR: Etiology of sockeye salmon "virus" disease. US Fish Wildl Serv Spec Sci Rep Fish 1959, 296:1-10.

5. Wingfield WH, Fryer JL, Pilcher KS: Properties of sockeye salmon virus (Oregon strain). Proc Soc Exp Biol Med 1969, 30:1055-1059.

6. Bootland LM, Leong JC: Infectious hematopoietic necrosis virus. Fish diseases and disorders. CAB International, New YorkWoo PTK, Bruno DW 1999, 3:57-121.

7. Kurath G, Ahern KG, Pearson GD, Leong JC: Molecular cloning of the six mRNA species of infectious hematopoietic necrosis virus, a fish 
rhabdovirus, and gene order determination by R-loop mapping. J Virol 1985, 53:469-476.

8. LaPatra SE, Lauda KA, Morton AW: Antigenic and virulence comparisons of eight isolates of infectious hematopoietic necrosis virus from the Hagerman Valley, Idaho, USA. Proceedings of the Second International Symposium on Viruses of Lower Vertebrates Corvallis, OR: Oregon State University 1991, 125-132.

9. LaPatra SE, Lauda KA, Jones GR: Antigenic variants of infectious hematopoietic necrosis virus and implications for vaccine development. Dis Aquat Organ 1994, 20:119-126.

10. Kurath G, Garver KA, Troyer RM, Emmenegger EJ, Einer-Jensen K, Anderson ED: Phylogeography of infectious haematopoietic necrosis virus in North America. J Gen Virol 2003, 84:803-814.

11. Troyer RM, LaPatra SE, Kurath G: Genetic analyses reveal unusually high diversity of infectious hematopoietic necrosis virus in rainbow trout aquaculture. J Gen Virol 2000, 81:2823-2832.

12. Troyer RM, Kurath G: Molecular epidemiology of infectious hematopoietic necrosis virus reveals complex virus traffic and evolution within southern Idaho aquaculture. Dis Aquat Organ 2003, 55:175-185.

13. Schütze H, Enzmann PJ, Kuchling R, Mundt E, Niemann H, Mettenleiter TC: Complete genomic sequence of the fish rhabdovirus infectious hematopoietic necrosis virus. J Gen Virol 1995, 76:2519-2527.

14. Morzunov SP, Winton JR, Nichol ST: The complete genome structure and phylogenetic relationship of infectious hematopoietic necrosis virus. Virus Res 1995, 38:175-192.

15. Amos KH: Procedures for the detection and identification of certain fish pathogens. Fish Health Section American Fisheries Society, Corvallis, 3 1985, 6-21.

16. Fijan N, Sulimanovic D, Bearzotti M, Muzinic D, Zwillenberg LO, Chilmonczyk S, Vautherot JF, de Kinkelin P: Some properties of the epithelioma papulosum cyprini (EPC) cell line from carp Cyprinus carpio. Ann Virol (Paris) 1983, 134:207-220.

17. Ammayappan A, Vakharia VN: Molecular characterization of the Great Lakes viral hemorrhagic septicemia virus (VHSV) strain from USA. Virol $J$ 2009, 6:171.

18. Nicholas KB, Nicholas HBJ, Deerfield DW: GeneDoc: analysis and visualization of genetic variation. EMBNEW NEWS 1997, 4:14.

19. Tamura K, Dudley J, Nei M, Kumar S: MEGA4: Molecular evolutionary genetics analysis (MEGA) software version 4.0. Mol Biol Evol 2007, 24:1596-1599.

20. Kurath $G$, Leong JA: Characterization of infectious hematopoietic virus mRNA species reveals a nonvirion rhabdovirus protein. J Virol 1985, 53:462-468.

21. Schnell MJ, Buonocore L, Whitt MA, Rose JK: The minimal conserved transcription stop-start signal promotes stable expression of a foreign gene in vesicular stomatitis virus. J Virol 1996, 70:2318-2323.

22. Wertz GW, Whelan S, LeGrone A, Ball LA: Extent of terminal complementarity modulates the balance between transcription and replication of vesicular stomatitis virus RNA. Proc Natl Acad Sci 1994 91:8587-8591.

23. Banerjee AK: Transcription and replication of rhabdoviruses. Microbiol Rev 1987, 51:66-87.

24. Barr JN, Whelan SP, Wertz GW: cis-Acting signals involved in termination of vesicular stomatitis virus mRNA synthesis include the conserved AUAC and the U7 signal for polyadenylation. J Virol 1997, 71:8718-8725.

25. Barr JN, Wertz GW: Polymerase slippage at vesicular stomatitis virus gene junctions to generate poly (A) is regulated by the upstream $3^{\prime}-A U A C-5^{\prime}$ tetranucleotide: implications for the mechanism of transcription termination. J Virol 2001, 75:6901-6913.

26. Whelan SP, Wertz GW: Regulation of RNA synthesis by the genomic termini of vesicular stomatitis virus: identification of distinct sequences essential for transcription but not replication. J Virol 1999, 73:297-306.

27. Newcomb WW, Brown JC: Role of the vesicular stomatitis virus matrix protein in maintaining the viral nucleocapsid in the condensed form found in native virions. J Virol 1981, 39:295-299.

28. Mebatsion T, Weiland F, Conzelmann KK: Matrix protein of rabies virus is responsible for the assembly and budding of bullet-shaped particles and interacts with the transmembrane spike glycoprotein G. J Virol 1999, 73:242-250.

29. Finke S, Conzelmann KK: Replication strategies of rabies virus. Virus Res 2005, 111:120-131.
30. Kassis R, Larrous F, Estaquier J, Bourhy H: Lyssavirus matrix protein induces apoptosis by a TRAlL-dependent mechanism involving caspase-8 activation. J Virol 2004, 78:6543-6555.

31. Thoulouze MI, Bouguyon E, Carpentier C, Bremont M: Essential role of the NV protein of Novirhabdovirus for pathogenicity in rainbow trout. J Virol 2004, 78:4098-4107.

32. Alonso M, Kim CH, Johnson MC, Pressley M, Leong JA: The NV gene of snakehead rhabdovirus (SHRV) is not required for pathogenesis, and a heterologous glycoprotein can be incorporated into the SHRV envelope. J Virol 2004, 78:5875-5882.

33. Bearzotti M, Monnier AF, Vende $\mathrm{P}$, Grosclaude J, de Kinkelin P, Benmansour A: The glycoprotein of viral hemorrhagic septicemia virus (VHSV): antigenicity and role in virulence. Vet Res 1995, 26:413-422.

34. Huang C: Mapping of antigenic sites of infectious hematopoietic necrosis virus glycoprotein. PhD thesis, University of Washington, Seattle, USA 1993.

35. Kim CH, Winton JR, Leong JC: Neutralization-resistant variants of infectious hematopoietic necrosis virus have altered virulence and tissue tropism. J Virol 1994, 68:8447-8453.

doi:10.1186/1743-422X-7-10

Cite this article as: Ammayappan et al: Molecular characterization of the virulent infectious hematopoietic necrosis virus (IHNV) strain 22090. Virology Journal 2010 7:10.

\section{Publish with Bio Med Central and every scientist can read your work free of charge}

"BioMed Central will be the most significant development for disseminating the results of biomedical research in our lifetime. "

Sir Paul Nurse, Cancer Research UK

Your research papers will be:

- available free of charge to the entire biomedical community

- peer reviewed and published immediately upon acceptance

- cited in PubMed and archived on PubMed Central

- yours - you keep the copyright 